\title{
Phase 1 Trial of Adalimumab in Focal Segmental Glomerulosclerosis (FSGS): II. Report of the FONT (Novel Therapies for Resistant FSGS) Study Group
}

\author{
Melanie S. Joy, PharmD ${ }^{1,2}$, Debbie S. Gipson, MD, MSPH ${ }^{1}$, Leslie Powell, RN, CPNP ${ }^{1}$, \\ Jacqueline MacHardy ${ }^{1}$, J. Charles Jennette, MD $^{3}$, Suzanne Vento, RN ${ }^{4}$, Cynthia Pan, MD ${ }^{5}$, \\ Virginia Savin, $\mathrm{MD}^{5}$, Allison Eddy, MD ${ }^{6}$, Agnes B. Fogo, MD ${ }^{7}$, Jeffrey B. Kopp, MD ${ }^{8}$, Daniel \\ Cattran, MD, FRCP C ${ }^{9}$, and Howard Trachtman, MD ${ }^{4}$, \\ ${ }^{1}$ University of North Carolina at Chapel Hill, UNC Kidney Center and Division of Nephrology and \\ Hypertension, Chapel Hill, NC \\ ${ }^{2}$ University of North Carolina at Chapel Hill, School of Pharmacy, Division of Pharmacotherapy and \\ Experimental Therapeutics, Chapel Hill, NC \\ ${ }^{3}$ University of North Carolina at Chapel Hill, Department of Pathology, Chapel Hill, NC \\ ${ }^{4}$ Schneider Children's Hospital of North Shore-LIJ Health System, Division of Nephrology, New \\ Hyde Park, NY \\ ${ }^{5}$ Medical College of Wisconsin, Departments of Pediatrics and Medicine, Division of Nephrology, \\ Milwaukee, WI \\ ${ }^{6}$ Seattle Children's Hospital, Division of Nephrology, Seattle, WA \\ ${ }^{7}$ Vanderbilt University Medical Center, Department of Pathology, Nashville, TN \\ ${ }^{8}$ Kidney Disease Section, NIDDK, Kidney Diseases Branch, National Institutes of Health, Bethesda, \\ MD \\ ${ }^{9}$ Toronto General Research Institute, University Health Network, Toronto, Ontario, Canada
}

\begin{abstract}
Background-Patients with primary focal segmental glomerulosclerosis (FSGS) resistant to current treatment regimens are at high risk of progression to end stage kidney disease. Antifibrotic agents, such as tumor necrosis factor $\alpha$ (TNF- $\alpha$ ) antagonists, are a promising strategy to slow or halt the decline in renal function, based on preclinical and clinical data.
\end{abstract}

Study Design-Phase I clinical trial to assess the pharmacokinetics, tolerability, and safety of adalimumab, a human monoclonal antibody to TNF- $\alpha$.

Setting and Participants-Ten patients (4 male and 6 female), age $16.8 \pm 9.0 \mathrm{yr}$, and estimated GFR $105 \pm 50 \mathrm{~mL} / \mathrm{min} / 1.73 \mathrm{~m}^{2}$, were studied as out-patients

(C) 2009 The National Kidney Foundation, Inc. Published by Elsevier Inc. All rights reserved.

*Corresponding Author: Howard Trachtman MD Schneider Children's Hospital Division of Nephrology 269-01 76 ${ }^{\text {th }}$ Avenue New Hyde Park NY 11040 Tel: 718-470-3423 FAX: 718-470-0887 trachtma@lij.edu.

Publisher's Disclaimer: This is a PDF file of an unedited manuscript that has been accepted for publication. As a service to our customers we are providing this early version of the manuscript. The manuscript will undergo copyediting, typesetting, and review of the resulting proof before it is published in its final citable form. Please note that during the production process errors may be discovered which could affect the content, and all legal disclaimers that apply to the journal pertain.

Financial Disclosure: None to report. 
Intervention-Adalimumab, $24 \mathrm{mg} / \mathrm{m}^{2}$ every 14 days for 16 weeks (total 9 doses)

Outcomes-Pharmacokinetic assessment, tolerability, and safety

Measurements-Estimated glomerular filtration rate, proteinuria, and pharmacokinetic assessment after initial dosing and steady state

Results-Pharmacokinetic evaluation indicated that the area under the curve was decreased by $54 \%$ $(\mathrm{P}<0.001)$ and clearance was increased by $160 \%(\mathrm{P}<0.01)$ in patients with resistant FSGS compared to healthy controls and patients with rheumatoid arthritis. Adalimumab was well tolerated with no serious adverse events or infectious complications attributable to the drug. Proteinuria declined by $\geq 50 \%$ in 4 of 10 treated patients.

Limitations-Insufficient power to assess safety or efficacy of adalimumab therapy for patients with resistant FSGS

Conclusions-Pharmacokinetic assessment demonstrated increased clearance of adalimumab in patients with resistant primary FSGS and validated the need for evaluating the disposition of novel therapies in this disease to define appropriate dosing regimens. The study provides a rationale to evaluate efficacy of adalimumab as an antifibrotic agent for resistant FSGS in Phase II/III clinical trials.

\section{Keywords}

FSGS; pharmacokinetics; nephrotic syndrome; adalimumab; tumor necrosis factor- $\alpha$; antifibrotic

\section{INTRODUCTION}

Adalimumab is a human monoclonal antibody to tumor necrosis factor $\alpha$ (TNF- $\alpha)$. It is approved by the US Food and Drug Administration (FDA) for use as an anti-inflammatory agent to treat adults with rheumatoid arthritis, ankylosing spondylitis, Crohn disease, or psoriasis and children with juvenile idiopathic arthritis $(1,2,3)$. However, despite increasing use of this agent, there is little information about the effect of anti-TNF- $\alpha$ agents in renal disorders $(4,5)$.

Experimental and clinical data support the role of TNF- $\alpha$ in the pathogenesis of a wide spectrum of kidney diseases including FSGS. In Buffalo/Mna rats that spontaneously develop nephrotic syndrome and FSGS, there is upregulation of renal expression of TNF- $\alpha$ (350-fold higher than control levels) before the onset of proteinuria (6).TNF- $\alpha$ levels are elevated in plasma and urine obtained from patients with FSGS $(7,8)$. Moreover, the ratio of TNF to interleukin 13 (IL-13) levels in serum, an index of inflammation, remains high in patients who are unresponsive to 4 weeks of corticosteroid treatment and who presumably have FSGS (9). Production of TNF- $\alpha$ is enhanced in cultured peripheral blood mononuclear cells obtained from children with steroidresistant nephrotic syndrome and FSGS $(10,11)$. Expression of the cytokine is also increased within the renal parenchyma of patients with FSGS and TNF- $\alpha$ immunoreactivity correlates with the extent of interstitial fibrosis (12). Finally, TNF- $\alpha$ causes endothelial cell injury and increases glomerular permeability in vitro (13); these two adverse effects are reversed by extracts of the herbs, Ganoderma lucidum and Tripterygium wilfordii Hook F, respectively $(14,15)$. Taken together, these findings support a role of TNF- $\alpha$ in mediating proteinuria and renal fibrosis in FSGS.

There are case reports suggesting the efficacy of anti-TNF- $\alpha$ therapies in patients with nephrotic syndrome $(16,17)$. In contrast, there is evidence that anti-TNF- $\alpha$ agents can induce glomerular injury that manifests as membranous nephropathy or immune complex nephritis (18). These 
findings underscore the need to systematically assess the application of anti-TNF- $\alpha$ therapy in patients with primary FSGS.

Despite the potential benefit of adalimumab therapy in primary and secondary glomerulopathies, there are no data to guide dosage recommendations for monoclonal antibodies in these diseases (3). In glomerular disorders, a number of factors could alter monoclonal antibody pharmacokinetics (pharmacokinetics) and mandate dose adjustment to achieve safe and therapeutic drug levels. Adalimumab is an IgG protein (molecular weight of $148 \mathrm{kDa}$ ) and massive urinary losses could result in lower peak levels and reduced cumulative exposure to the biological agent. Extracellular fluid volume status can be altered in nephrotic syndrome resulting in potential changes in the volume of distribution of adalimumab. Finally, the effect of nephrotic syndrome on bioavailability of subcutaneously injected drugs has not been systematically studied.

The primary purpose of the first portion of the Novel Therapies for Resistant FSGS (FONT) study was to evaluate pharmacokinetics characteristics, tolerability, and safety of agents that hold promise as antifibrotic therapies. The first two agents selected for testing were rosiglitazone and adalimumab. The findings for rosiglitazone were recently published (19). In this report, we summarize the Phase I evaluation of adalimumab in patients with resistant primary FSGS. Secondary objectives were to determine the effect of clinical parameters and demographic variables on adalimumab pharmacokinetics.

\section{METHODS}

Patients

Patients, 2-41 years of age, with primary FSGS and estimated GFR (GFRe) $>40 \mathrm{~mL} / \mathrm{min} / 1.73$ $\mathrm{m}^{2}$ were eligible to participate in the FONT study. Eligibility was confirmed by review of the kidney biopsy by a central pathologist. Patients were resistant to glucocorticoids prescribed in accord with current practice guidelines and to one additional therapy such as mycophenolate mofetil, azathioprine, cyclosporine, or tacrolimus. The protocol was approved by the Institutional Review Board at each site and patient or parent/ guardian consent (and assent where appropriate) was obtained prior to enrollment.

Participants were off all immunosuppressive medications except for minimal doses of glucocorticoids for at least 4 weeks prior to enrollment. Therapy with angiotensin converting enzyme inhibitors and angiotensin receptor blockers was permitted, provided dosages were not modified during the study except for safety indications. In the FONT Phase I trial, patients were assigned to receive rosiglitazone or adalimumab. This report summarizes the results in the latter group.

The adalimumab (Humira ${ }^{\circledR}$, Abbott Laboratories Inc., www.abbott.com) dose was $24 \mathrm{mg} /$ $\mathrm{m}^{2}$ injected subcutaneously every 14 days, maximum $40 \mathrm{mg}$. Adalimumab was given for 16 weeks and patients were evaluated at Weeks $0,1,2,4,8,12$, and 16 . The following clinical and laboratory data were measured at each assessment: vital signs, height, weight, severity of edema, serum creatinine, estimated glomerular filtration rate (eGFR; calculated by using the Cockroft-Gault equation if $\geq 18 \mathrm{yr}$ and age- and sex-appropriate Schwartz formula for $<18$ $\mathrm{yr}$ ), urine protein-creatinine ratio in a first morning specimen, and serum albumin, fasting total cholesterol, AST, and ALT concentrations. CH50 and ANA titers were measured at Weeks 0, 8 and 16.

All adverse effects were tabulated and causal relationship to adalimumab was determined by the site investigator. Patient satisfaction with therapy was assessed at Week 16 using the Treatment Satisfaction Questionnaire for Medications (TSQM) instrument (20). 


\section{Pharmacokinetic Study}

Patients underwent two comprehensive pharmacokinetics assessments -- an initial pharmacokinetics study with the first dose of adalimumab at Week 0 and a steady state assessment after patients had received adalimumab for 16 weeks.

Patients were admitted to the General Clinical Research Unit. Patients were fasting at the start and then fed a standard diet throughout the procedure. After obtaining a baseline blood sample, patients received their biweekly dose of adalimumab. Additional serum samples were obtained at $2,8,12,30$, and $42 \mathrm{hr}$. Approximately $15 \mathrm{~mL}$ of blood was drawn during each pharmacokinetics study. Urine was collected from 0-2, 2-12, 12-24, 24-36, and 36-48 hr for measurement of protein excretion. A validated assay to measure urinary adalimumab levels was unavailable for this study. Blood samples were immediately centrifuged for $10 \mathrm{~min}$ at $4^{\circ}$ $\mathrm{C}$, and serum was stored at $-80^{\circ} \mathrm{C}$ until assayed.

\section{Analytical methods}

Serum adalimumab concentrations were quantified by a validated two-antigen sandwich ELISA (under supervision of Abbott Laboratories). The assay sensitivity limit was $0.25 \mu \mathrm{g} /$ $\mathrm{mL}$ serum. The interassay accuracy was $101-102 \%$ and the precision was equal to $4.7 \%$ at quality control sample concentrations of $6.0-36.1 \mathrm{ng} / \mathrm{mL}$. Serum TNF- $\alpha$ levels were measured using a commercial ELISA (R\&D Systems, www.rndsystems.com).

\section{Pharmacokinetics Analysis}

Non-compartmental pharmacokinetics analysis of adalimumab was conducted using WinNonlin v4.1 (Pharsight, www.pharsight.com) with linear up-log down for AUC determination. Non-compartmental analysis was justified because previous data demonstrated stationary pharmacokinetics. The following pharmacokinetics parameters were analyzed: peak plasma concentration $\left(C_{\max }\right)$, time to peak drug concentration $\left(T_{\max }\right)$, AUC from time 0 to infinity $\left(A U C_{0-\infty}\right)$ for single dose, AUC from time 0 to $336 \mathrm{hr}\left(A U C_{0-336}\right)$ for steady state dosing, apparent clearance $(C l / F)$, apparent volume of distribution $(V z / F)$, and half-life $\left(T_{1 / 2}\right)$. In order to eliminate differences secondary to the amount of adalimumab administered, data for $C_{\max }, C_{t r}$ (trough plasma concentration), and $A U C_{0-\infty}$ data were adjusted to a dose of 40 $\mathrm{mg}$. Clearance data were scaled to a weight of $70 \mathrm{~kg}$ and then raised to a power of 0.75 to minimize differences related to body size (21).

\section{Statistical methods}

Data are presented as mean \pm standard deviation (SD). Descriptive analyses for pharmacokinetics parameters, demographic variables, and laboratory tests include mean, standard deviation, and median as appropriate. Differences between groups were assessed with analysis of variance followed by paired comparisons using a t-test with a Bonferroni correction. Spearman correlations were determined for key clinical characteristics (serum albumin, urine protein-creatinine ratio, eGFR, age, BSA) versus each pharmacokinetics parameter of interest (AUC, $C l / F, V z / F, T_{1 / 2}, C_{t r}, C_{\max }$ ). The correlations and resultant $\mathrm{P}$ values from the univariant assessments were analyzed for inclusion into a multiple regression model for prediction of $\mathrm{Cl} /$ $F, C_{t r}$, and $C_{\max }$ for adalimumab. Data that did not follow a normal distribution were transformed or ranked prior to model assessments. Model building consisted of multiple regression analysis with forward selection. The final model was selected based on significance of each clinical variable as a predictor of the adalimumab pharmacokinetics outcome as well as the overall $R^{2}$. $P$ values $<0.05$ were considered significant and given the exploratory nature of the study, $\mathrm{P}$ values $0.05-0.10$ were considered to show a trend 


\section{RESULTS}

\section{Patients}

Figure 1 summarizes the number of patients who were screened and enrolled in the FONT Phase I trial. Ten patients were assigned to adaliumab with $20 \%$ having collapsing, $10 \%$ cellular, 20\% tip, and 50\% not otherwise specified (NOS) lesions. Nine participants completed the 16-week treatment period and underwent all of the laboratory evaluations. One patient exited after 12 weeks because of refractory proteinuria and severe edema, which prompted the site investigator to restart treatment with tacrolimus. Patients were 16.8 $\pm 9.0 \mathrm{yr}$ (range: 6-36 yr), $40 \%$ were prepubertal, $60 \%$ female, $30 \%$ nonwhite, and BSA was $2.2 \pm 1.0 \mathrm{~m}^{2}$ (Table 1). Concomitant medications included HMG CoA reductase (3-hydroxy-3-methylglutaryl coenzyme A) inhibitors (30\%), ACE inhibitors/angiotensin receptor blocking drugs (100\%), diuretics (40\%), and low-dose prednisone (20\%).

The key laboratory results at Weeks 0 and 16 are presented in Table 2. Group level comparisons in urine protein-creatinine ratio, GFRe, and serum albumin were not significant. In the 9 patients who completed the 16-week Treatment Period, 4 achieved at least a 50\% reduction in proteinuria, with the decline beginning at Week 2 and reaching a nadir at Week 16. In no case did the urinary protein excretion decline to normal.

No significant changes were noted in body weight, blood pressure, hematocrit, liver function tests, CH50 level (data not shown), or ANA titer (Table 3). Serum TNF- $\alpha$ levels were unaltered by the 16 week course of adalimumab therapy $(3885 \pm 3223$, pre-treatment versus $4721 \pm 3808$ $\mathrm{pg} / \mathrm{ml}$, post-treatment, $\mathrm{P}=0.6$ ).

\section{Pharmacokinetics}

Adalimumab pharmacokinetics data were available for all 10 patients at the single and steadystate evaluations. One patient who withdrew after 12 weeks had the steady state pharmacokinetics evaluation performed at that time. Because the single dose half-life in the FONT study was 159 hours, 12 weeks represented steady state conditions and pharmacokinetics results are presented for the full group of 10 patients. The adalimumab doses at the initial and final pharmacokinetics evaluation were $33.7 \pm 8.8 \mathrm{mg}$. Concentration versus time profiles for single dose adalimumab administration are presented in Figure 2.

The adalimumab pharmacokinetics parameters are provided in Table 4. Data from rheumatoid arthritis patients after a single dose of antibody are provided for comparison $(22,23)$. The published results for $C l / F$ and $A U C_{0-\infty}$ for adalimumab were not adjusted to a $70 \mathrm{~kg}$ body weight; however, the average weight in these studies was $69.7 \mathrm{~kg}$. Initial dose and steady state pharmacokinetics parameters from the FONT patients were similar with the exception of $\mathrm{Cl} /$ $F$, which was higher at steady state versus initial dosing $(\mathrm{P}<0.05)$. Single dose pharmacokinetics parameters ( $T_{\max }, C_{\max }$ (dose corrected), $T_{1 / 2}, A U C_{0-\infty}, V z / F$, and $\left.C l / F\right)$ in the FSGS group were different than in patients with rheumatoid arthritis. Steady-state parameters from FONT patients could not be compared to the rheumatoid arthritis cohort because these data were not obtained in the latter population. $T_{\max }$ was reduced almost 3 -fold $(55 \pm 62$ vs $130 \pm 55 \mathrm{hr}, \mathrm{P}<0.02)$ in the FONT patients, suggesting faster absorption from the injection site. However, $C_{\max }$ was also lower in FSGS patients compared to those with rheumatoid arthritis, $9.2 \pm 4.1$ versus $13.7 \pm 2.7 \mu \mathrm{g} / \mathrm{mL}$, respectively, $\mathrm{P}<0.02$.

The steady state half-life $\left(T_{1 / 2 s s}\right)$ demonstrated an inverse linear relationship with the urine protein-creatinine ratio and direct correlation with the serum albumin concentration. The $T_{1 / 2 s s}$ was shorter in FSGS patients who exhibited higher urine protein-creatinine ratio ratios and lower serum albumin levels (Figures $3 \mathrm{a}$ and $3 \mathrm{~b}$ ). The ranked $T_{1 / 2 s s}$ versus urine proteincreatinine ratio showed a correlation coefficient, $r$ value -0.899 (95\% CI -0.9761 to -0.6207 ), 
$\mathrm{r}^{2}=0.8082(\mathrm{P}<0.001)$. Linear correlation analysis between ranked $T_{1 / 2 s s}$ and serum albumin indicated that the r value was 0.7586 , (95\% CI 0.2467 to 0.9395$), \mathrm{r}^{2}=0.5755$ ( $\left.\mathrm{P}=0.01\right)$. A similar but less significant relationship was noted when half life versus urine protein-creatinine ratio or serum albumin was assessed after the first dose. Weaker relationships were found when the $A U C_{s s}$ and $C l / F_{s s}$ were plotted against urine protein-creatinine ratio. There were 3 outliers to these relationships: 2 patients who had significantly lower $A U C_{s s}$ and higher $C l / F_{s s}$ versus urine protein-creatinine ratio correlations than the best fit line and 1 patient who had an extremely high urine protein-creatinine ratio $(29 \mathrm{mg} / \mathrm{mg})$ and moderate $A U C_{s s}$ and $C l / F_{s s}$ values. Reanalysis of $A U C_{s s}$ and $C l / F_{s s}$ versus urine protein-creatinine ratio linear correlational analysis without these 3 patients demonstrated highly significant relationships $(\mathrm{P}<0.002$ and $\mathrm{P}<0.02$, respectively) (Figures $4 \mathrm{a}$ and $4 \mathrm{~b}$ ). A significant negative relationship between $V z / F$ and urine protein-creatinine ratio at steady state was demonstrated; $\mathrm{r}-0.9193$ (95\% CI -0.9948 to -0.1955$), \mathrm{r}^{2} 0.8451$.

Multiple regression analyses were employed to assess the contribution of all variables from the univariate analyses to the prediction of steady state pharmacokinetics responses $\left(C l / F_{s s}\right.$, $C_{\text {trss }}, A U C_{s s}, C_{\text {maxss }}$ ). $\mathrm{T}_{1 / 2}$ was not included because it represents a hybrid variable of $V z / F$ and $C l / F$. Two relationships of similar magnitude were determined for $C l / F_{s s}$ with race constant in both models and albumin or urine protein-creatinine ratio reflecting the second variable in the respective models. Race was coded as " 1 " if white and " 2 " if nonwhite.

$\mathrm{Cl} / \mathrm{F}_{\mathrm{ss}}=-51.143+52.124 \times($ race $)+2.429 \times($ urine protein-creatinine ratio $)$

$\mathrm{R}^{2} 61.38 \%, \mathrm{P}=0.04$

Equation 1

$\mathrm{Cl} / \mathrm{F}_{\mathrm{sS}}=10.231+68.68 \times($ race $)-10.845 \times($ ranked albumin $)$

$\mathrm{R}^{2} 85.54 \%, \mathrm{P}=0.001$

Equation 2

Modeling of equations for the prediction of $C_{t r}$ and $C_{\max }$ was also evaluated because the predicted $C_{t r}$ at $80 \%$ Emax would be $4-8 \mu \mathrm{g} / \mathrm{mL}$ based on a biweekly $40 \mathrm{mg}$ dose utilized in rheumatoid arthritis patients (24). Only 3 FONT patients achieved a $C_{t r}$ between $4-8 \mu \mathrm{g} / \mathrm{mL}$. Patients with "therapeutic" $C_{t r}$ concentrations had changes in GFRe $(+29.3 \pm 71.1 \mathrm{~mL} / \mathrm{min} /$ $\left.1.73 \mathrm{~m}^{2}\right)$, urine protein-creatinine ratio $(-10.4 \pm 8.00)$, and serum albumin $(+1.03 \pm 1.10 \mathrm{~g} / \mathrm{dL})$ that represented clinical improvements. In contrast, the 7 patients who did not achieve $C_{t r} \geq 4$ $\mu \mathrm{g} / \mathrm{mL}$ had worsening and/or less favorable clinical laboratory outcomes, based on GFRe $\left(-10.9 \pm 24.5 \mathrm{~mL} / \mathrm{min} / 1.73 \mathrm{~m}^{2}\right)$, urine protein-creatinine ratio $(-0.79 \pm 5.83)$, and serum albumin $(-0.29 \pm 0.49 \mathrm{~g} / \mathrm{dL})$. The serum albumin concentration and urine protein-creatinine ratio independently predicted $C_{\text {trss }}$ in the FSGS patients.

$\ln C_{t r s s}=8.451-0.1946 \times($ urine protein-creatinine ratio) $\mathrm{R}^{2} 76.46 \%, \mathrm{P}<0.001$

Equation 3

$$
\begin{gathered}
\ln C_{t r s s}=3.390+0.5650 \times(\text { ranked albumin }) \\
\mathrm{R}^{2} 62.30 \%, \mathrm{P}=0.007
\end{gathered}
$$

Equation 4

No linear relationships or multivariable models were found that predicted $C_{\max }$ values. 


\section{Tolerability}

Patient tolerance of adalimumab was assessed by the TSQM questionnaire, which provides data in four domains (maximal score of 100 in each category, higher scores indicate better tolerance). The scores were: effectiveness $61 \pm 21$, side effects $92 \pm 18$, convenience $71 \pm 20$, and global satisfaction $59 \pm 26$. The results were similar to those previously reported with rosiglitazone (19), except for slightly lower scores for convenience and global satisfaction. This probably reflects the need for injections to administer the adalimumab.

\section{Safety}

Adverse events were generally mild (Table 5). There was a total of 9 events, with only 1 deemed to be "probably related" to adalimumab therapy. This event, an injection site reaction, was mild. Two severe adverse events were noted (edema, bilateral avascular necrosis) but they were not attributed to adalimumab and the $C_{t r}$ was $<4 \mu \mathrm{g} / \mathrm{mL}$. Three events were recorded as fever, cough, and/or body aches and were not considered drug-related. Only 1 of these 3 patients achieved $C_{t r}$ concentration, $10 \mu \mathrm{g} / \mathrm{mL}$, which was outside the therapeutic range of $4-8 \mu \mathrm{g} / \mathrm{mL}$. None of the patients required discontinuation of adalimumab because of adverse events.

\section{DISCUSSION}

This is the second report of the FONT study group and complements our description of the pharmacokinetics, tolerability, and safety of rosiglitazone in patients with resistant FSGS (19). The findings are consistent with studies demonstrating the potential benefit of inhibition of TNF- $\alpha$ with etanercept (25) or pentoxifylline (26) in small cohorts of patients with idiopathic membranous nephropathy. The current results with adalimumab are the first to document different pharmacokinetics of a human monoclonal antibody in patients with primary FSGS and nephrotic syndrome. Importantly, pharmacokinetics parameters $\left(T_{\max }, C_{\max }, T_{1 / 2}, A U C, V /\right.$ $F$, and $C l / F$ ) differed in FSGS patients compared to a reference population of rheumatoid arthritis patients $(22,23)$. Specifically, the FSGS population attained lower $C_{\text {max }}, A U C, V / F$, shorter $T_{\max }$ and $T_{1 / 2}$, and higher $C l / F$ values after a single-dose compared to rheumatoid arthritis patients, reflecting diminished exposure to adalimumab.

Significant relationships between urine protein-creatinine ratio or serum albumin and half life of adalimumab were predicted by univariate correlational analyses. Although the statistical strength of the relationships with ranked albumin and proteinuria varied depending on the pharmacokinetics parameter, measurement of protein excretion may be more practical because it can be applied to individual patients. No relationship between half life and GFRe was appreciated. This suggests a novel approach to dosing antibodies in nephrotic patients based on a marker of disease severity, i.e., urine protein-creatinine ratio. This would be analogous to dosing drugs that are eliminated by the kidney via glomerular filtration by calculating the creatinine clearance. In nephrotic syndrome, excessive amounts of large molecular weight molecules such as albumin are lost in the urine or the interstitial space. Urinary losses of adalimumab were not measured in this study because a validated assay was unavailable. However, renal IgG clearance $\left(0.055 \mathrm{~mL} / \mathrm{min} / 1.73 \mathrm{~m}^{2}\right)$ has been reported to be one-third the albumin clearance $\left(0.16 \mathrm{~mL} / \mathrm{min} / 1.73 \mathrm{~m}^{2}\right)$ in 15 patients with FSGS and normal GFR (27). This represented a loss of $2216 \mathrm{mg} / \mathrm{m}^{2} /$ day and $199 \mathrm{mg} / \mathrm{m}^{2} /$ day of endogenous albumin and $\mathrm{IgG}$, respectively. Serum protein concentrations were reduced in those with renal losses of albumin and $\operatorname{IgG}(27)$.

We explored the relationship of urine protein-creatinine ratio to other pharmacokinetics variables in the FSGS patients. Since $C l / F$ is a primary pharmacokinetics variable and can significantly alter drug exposure $(A U C)$, we plotted $A U C$ and $C l / F$ versus urine proteincreatinine ratio. Although there was a linear relationship for the majority of our FSGS patients, 
three patients deviated from the relationship. At a urine protein-creatinine ratio of approximately 5, Cl/F values for 2 of 4 patients were 3-5 fold higher, and hence their data departed significantly from the line of identity. Additionally, the patient with the highest urine protein-creatinine ratio value $(29 \mathrm{mg} / \mathrm{mg})$, had a severely reduced $\mathrm{Cl} / \mathrm{F}$ from that predicted based on the line of identity. An alternative clearance mechanism besides urine proteincreatinine ratio may be activated in patients with higher than expected adalimumab clearances that is lacking in patients with severely reduced drug clearance.

The use of clinical factors to predict estimates of pharmacokinetics variables such as $C l / F$ and $C_{t r}$ was examined in order to design appropriate dosing regimens. In addition to albumin and urine protein-creatinine ratio, race predicted adalimumab $C l / F_{s s}$. Patients classified as "nonWhite" had a 2-fold increase in $\mathrm{Cl} / \mathrm{F}$ versus patients classified as "White". Differences in IgG $\mathrm{Cl} / \mathrm{F}$ based on race have not previously been reported. Validation studies are needed prior to drafting guidelines on dosing based on the findings in this study.

There was evidence of clinical improvement, manifested as increases in GFRe and serum albumin and decreases in urine protein-creatinine ratio in the FSGS patients whose adalimumab $C_{t r}$ exceeded $4 \mu \mathrm{g} / \mathrm{mL}$, the therapeutic target in rheumatoid arthritis (24). Patients with rheumatoid arthritis show strong dose-response relationships (28). Rheumatoid arthritis patients who develop anti-adalimumab antibodies demonstrate lower $C_{t r}$ and reduced response to therapy. Thus, antibody generation may cause lower than predicted adalimumab concentrations and lack of response in FSGS patients. Anti-adalimumab antibody levels were unavailable in the FONT Phase I study cohort. The safety data in our study did not demonstrate concentration-related side effects in patients with $C_{t r}>4 \mu \mathrm{g} / \mathrm{mL}$. Despite alterations in adalimumab pharmacokinetics characteristics in patients with resistant FSGS, the FDA approved dosage of $24 \mathrm{mg} / \mathrm{m}^{2}$ or $40 \mathrm{mg}$ maximum single dose does not appear to be unsafe in this patient population.

There were no serious adverse events attributed to adalimumab in this study. In particular, no patients developed infections or a new malignancy. This is encouraging given that adalimumab may be associated with serious infections such as reactivation of latent tuberculosis (29) and malignancies in immunosuppressed patient populations (30), even after fairly limited exposure times. None of the participants developed an elevated ANA titer, SLE-like syndrome, or de novo glomerular disease, rare events in adalimumab-treated patients $(18,31)$. Patients were treated for a relatively short period of time and were not receiving concomitant

immunosuppressive medications, factors that can influence the risk of serious adverse effects $(29,30,31)$. Adalimumab was not discontinued in any case because of other drug-related serious or minor adverse events. Despite the general safety and tolerance observed in this Phase I study, intensive surveillance for infections and malignancies will be mandatory in future Phase II and III clinical trials. This is underscored by the recent fatality related to disseminated histoplasmosis that occurred in a patient with rheumatoid arthritis who was enrolled in a gene therapy protocol and who was receiving anti-TNF- $\alpha$ therapy (32). This will help define the risk:benefit ratio of this therapy as an antifibrotic agent in patients with resistant primary FSGS and is germane in light of a recent report documenting successful use of anti-TNF- $\alpha$ treatment for recurrent FSGS post-kidney transplant and other kidney diseases $(33,34)$.

There are several limitations in this Phase I study. First, we could not measure urinary loses of adalimumab due to lack of a validated assay. Second, determination of human anti-human antibody titers were not done and need to incorporated in future Phase II studies. Third, this Phase I study was designed to assess pharmacokinetics, tolerability, and safety and not efficacy. It is difficult to extrapolate an estimate of efficacy, based on the heterogeneous response in this cohort. Finally, the small sample size and relative short duration of treatment were insufficient to define the full spectrum of potential side effects. 
In conclusion, this Phase I study demonstrated that the clearance of adalimumab is increased in patients with resistant primary FSGS. Clinical and laboratory characteristics such as race, proteinuria and serum albumin may enable prediction of drug handling in this population. The drug was well tolerated and safe in this small cohort with a limited duration of treatment. These results justify further Phase II testing of adalimumab as an antifibrotic agent to slow the progression of renal disease.

\section{Acknowledgments}

This work was presented in abstract form at the Annual Meeting of the American Society of Nephrology, November 2008, Philadelphia, PA. The authors thank Raymond Pica BS for performing the assay of the serum TNF- $\alpha$ levels.

Support: This work was supported by National Institutes of Health NIDDK grant 5R21-DK070341, the NIDDK intramural research program, and the General Clinical Research Centers program of the NIH National Center for Research Resources, via RR00046 (University of North Carolina at Chapel Hill) and RR018535 (North Shore-LIJ) .

\section{REFERENCES}

1. Lopez-Olivo MA, Kallen MA, Ortiz Z, Skidmore B, Suarez-Almazor ME. Quality appraisal of clinical practice guidelines and consensus statements on the use of biologic agents in rheumatoid arthritis: A systemic review. Arthritis Rheum 2008;59:1625-1638. [PubMed: 18975351]

2. Shah SB, Hanauer SB. Risks and benefits of the use of concomitant immunosuppressives and biologics in inflammatory bowel disease. Rev Gastroenterol Disord 2008;8:159-168. [PubMed: 18957923]

3. Lovell DJ, Ruperto N, Goodman S, Reiff A, Jung L, Jarasova K, Nemcova D, Mouy R, Sandborg C, Bohnsack J, Elewaut D, Foeldvari I, Gerloni V, Rovensky J, Minden K, Vehe RK, Weiner LW, Horneff G, Huppertz HI, Olson NY, Medich JR, Carcereri-De-Prati R, McIlraith MJ, Giannini EH, Martini A. Adalimumab with or without methotrexate in juvenile rheumatoid arthritis. N Engl J Med 2008;359:810-821. [PubMed: 18716298]

4. Felderman M. Many cytokines are very useful therapeutic targets in disease. J Clin Invest 2008;118:3533-3536. [PubMed: 18982159]

5. Li X, Magenheimer BS, Xia S, Johnson T, Wallace DP, Calvet JP, Li R. A tumor necrosis factor- $\alpha-$ mediated pathway promoting autosomal dominant polycystic kidney disease. Nature Med 2008;14:863-868. [PubMed: 18552856]

6. LeBerre L, Herve C, Buzelin F, Usal C, Soulillou JP, Dantal J. Renal macrophage activation and Th2 polarization precedes the development of nephrotic syndrome in Buffalo/Mna rats. Kidney Int 2005;68:2079-2090. [PubMed: 16221207]

7. Suranyi MG, Guasch A, Hall BM, Myers BD. Elevated levels of tumor necrosis factor- $\alpha$ in the nephrotic syndrome in humans. Am J Kid Dis 1993;21:251-259. [PubMed: 8447300]

8. Kacprzyk F, Chrzanowski W. Tumor necrosis factor (TNF) and interleukin-6 (IL-6) on patients with glomerulonephritis. Pol Arch Med Wewn 1996;96:224-233. [PubMed: 9122013]

9. Tain YL, Chen TY, Yang KD. Implications of serum TNF- $\beta$ and Il-13 in the treatment response of childhood nephrotic syndrome. Cytokine 2003;21:155-159. [PubMed: 12697154]

10. Lama G, Luongo I, Tirinio G, Borriello A, Carangio C, Salsano ME. T-lymphocyte populations and cytokines in childhood nephrotic syndrome. Am J Kid Dis 2002;39:958-965. [PubMed: 11979339]

11. Bakr A, Shokeir M, El-Chenawi F, El-Husseini F, Abdel-Rahman A, El-Ashry R. Tumor necrosis factor- $\alpha$ production from mononuclear cells in nephrotic syndrome. Pediatr Nephrol 2003;18:516520. [PubMed: 12707837]

12. Niemir ZI, Ondracek M, Dworacki G, Stein H, Waldherr R, Ritz E, Otto HF. In situ regulation of IL-10 reflects the activity of human glomerulonephritides. Am J Kid Dis 1998;32:80-92. [PubMed: 9669428]

13. McCarthy ET, Sharma R, Sharma M, Li JZ, Ge XL, Dileepan KN, Savin VJ. TNF- $\alpha$ increases albumin permeability of isolated rat glomeruli through the generation of superoxide. J Am Soc Nephrol 1998;9 (433):438. 
14. Futrakul FN, Panichakul T, Butthep P, Futrakul P, Jetanalin P, Putumraj S, Siriviriyakul P. Ganoderma lucidum suppresses endothelial cell cytotoxicity and proteinuria in persistent proteinuric focal segmental glomerulosclerosis. Clin Hemorheol Microcirc 2004;31:267-272. [PubMed: 15567896]

15. Sharma M, Li JZ, Sharma R, Artero M, Ge X, McCarthy ET, Wang HY, Savin V. Inhibitory effect of Tripterygium wilfordii multiglycoside on increased glomerular albumin permeability in vitro. Nephrol Dial Transplant 1997;12:2064-2068. [PubMed: 9351066]

16. Raveh D, Shemesh O, Ashkenazi YJ, Winkler R, Barak V. Tumor necrosis factor- $\alpha$ blocking agent as a treatment for nephrotic syndrome. Pediatr Nephrol 2004;19:1281-1284. [PubMed: 15338388]

17. Chin G, Luxton G, Harvey JM. Infliximab and nephrotic syndrome. Neph Dial Transplant 2005;20:2824-2826.

18. Stokes MB, Foster K, Markowitz GS, Ebrahimi F, Hines W, Kaufman D, Moore B, Wolde D, D’Agati VD. Development of glomerulonephritis during ant-TNF- $\alpha$ therapy for rheumatoid arthritis. Nephrol Dial Transplant 2005;20:1400-1406. [PubMed: 15840673]

19. Joy MS, Gipson DS, Dike M, Powell L, Thompson A, Vento S, Eddy A, Fogo AB, Kopp JB, Cattran DC, Trachtman H. Phase I trial of rosiglitazone in FSGS: I. Report of the FONT Study Group. Clin J Am Soc Nephrol 2009;4:39-47. [PubMed: 19073787]

20. Atkinson MJ, Sinha A, Hass SL, Colman SS, Kumar RN, Brod M, Rowland CR. Validation of a general measure of treatment satisfaction, the Treatment Satisfaction Questionnaire for Medication (TSQM), using a national panel study of chronic disease. Health Qual Life Outcomes 2004;2:12. [PubMed: 14987333]

21. Anderson BJ, Holford NH. Mechanism-based concepts of size and maturity in pharmacokinetics. Annu Rev Pharmacol Toxicol 2008;48:303-332. [PubMed: 17914927]

22. Weisman MH, Moreland LW, Furst DE, Weinblatt ME, Keystone EC, Paulus HE, Teoh LS, Velagapudi RB, Noertersheuser PA, Granneman GR, Fischkoff SA, Chartash EK. Efficacy, pharmacokinetics, and safety assessment of adalimumab, a fully human anti-tumor necrosis factoralpha monoclonal antibody, in adults with rheumatoid arthritis receiving concomitant methotrexate: A pilot study. Clin Ther 2003;25:1700-1721. [PubMed: 12860493]

23. Den Broeder A, van de Putte L, Rau R, Schattenkirchner M, Van Riel P, Sander O, Binder C, Fenner H, Bankmann Y, Velagapudi R, Kempeni J, Kupper H. A single-dose, placebo controlled study of the fully human anti-tumor necrosis factor-alpha antibody adalimumab (D2E7) in patients with rheumatoid arthritis. J Rheumatol 2002;29:2288-2298. [PubMed: 12415583]

24. Adalimumab [Investigator brochure]. Abbott Laboratories; Abbott Park, IL: Jun. 2003

25. Lionski S, Siamopoulos K, Theodoirou I, Papdimitraki E, Bertsias G, Boumpas D, Boletis J. Inhibition of tumor necrosis factor alpha in idiopathic membranous nephropathy: a pilot study. Neph Dial Transplant 2009;24:2144-2150.

26. Ducloux D, Bresson-Vautrin C, Chalopin J. use of pentoxifylline in membranous nephropathy. Lancet 2001;357:1672-1673. [PubMed: 11425374]

27. Ellis D, Buffone GJ. Protein clearances and selectivity determinations in childhood nephrosis: a reappraisal. Clin Chem 1981;27:1397-1400. [PubMed: 6168414]

28. Bartelds GM, Wijbrandts CA, Nurmohamen Mt, Stapel S, Lems WF, Aarder L, Dijkmans BAC, Tak PP, Wolbind GJ. Clinical response to adalimumab: relationship to anti-adalimumab antibodies and serum adalimumab concentrations in rheumatoid arthritis. Ann Rheum Dis 2007;66:921-926. [PubMed: 17301106]

29. Wallois RS. Tumor necrosis factor antagonists: structure, function, and tuberculosis risk. Lancet Infectious Dis 2008;8:601-611.

30. Bongartz T, Sutton AJ, Sweeting MJ, Buchan I, Matteson EL, Montori V. Anti-TNF antibody therapy in rheumatoid arthritis and the risk of serious infections and malignancies: Systematic review and meta-analysis of rare harmful effects in randomized clinical trial. JAMA 2006;295:2275-2285. [PubMed: 16705109]

31. Ramos-Casals M, Brito-Zeron P, Munoz S, Soria N, Galiana D, Bertolaccini L, Cuadrado MJ, Khamashta MA. Autoimmune diseases induced by TNF-targeted therapies: analysis of 233 cases. Medicine 2007;86:242-251. [PubMed: 17632266] 
32. Frank KM, Hogarth K, Miler JL, Mandal S, Mease PJ, Samulski J, Weisgerber GA, Hart J. Investigation of the cause of death in a gene-therapy trial. N Engl J Med 2009;361:161-169. [PubMed: 19587341]

33. Leroy S, Guigonia V, Bruckner D, Emai-Aglae V, Deschenes G, Bensman A, Ulinski T. Successful anti-TNF- $\alpha$ treatment in a child with posttransplant recurrent focal segmental glomerulosclerosis. Am J Transplant 2009;9:858-861. [PubMed: 19344472]

34. Ernandez T, Mayadas TN. Immunoregulatory role of TNF- $\alpha$ in inflammatory kidney diseases. Kidney Int 2009;76:262-276. [PubMed: 19436333] 


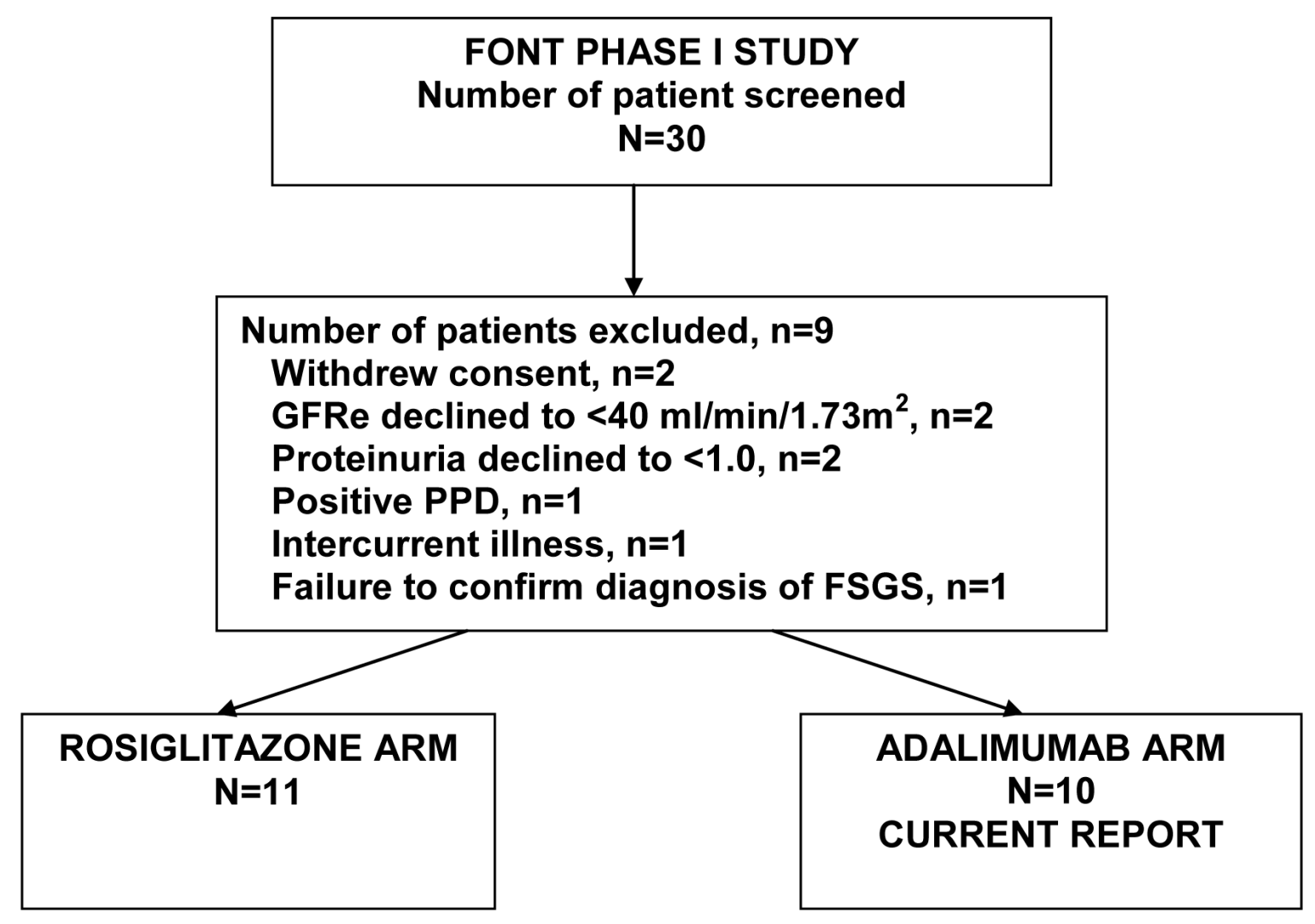

Figure 1.

CONSORT diagram summarizing patient screening and enrollment in the FONT Phase I trial 


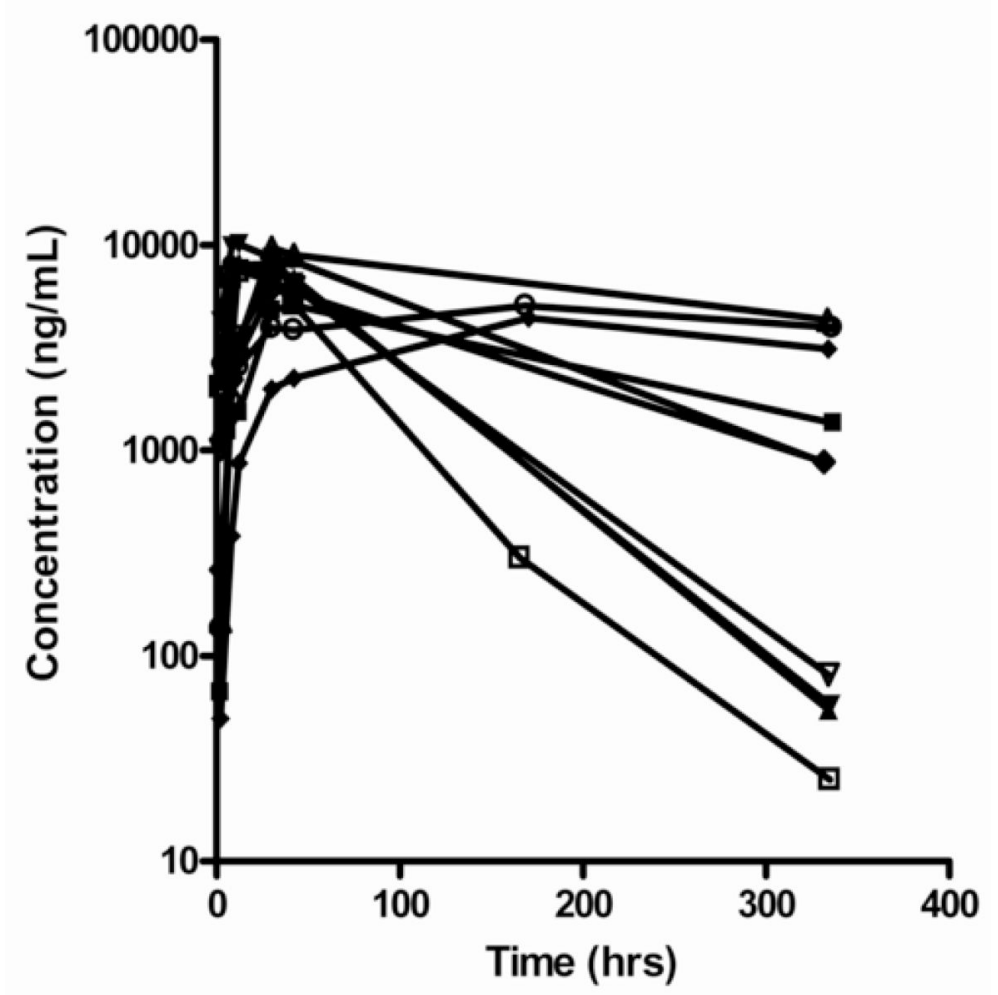

Figure 2.

Adalimumab concentration versus time curves after Single Dose. Note that the drug concentrations are provided as $\mathrm{ng} / \mathrm{mL}$ to enhance the clarity of the graphs. 

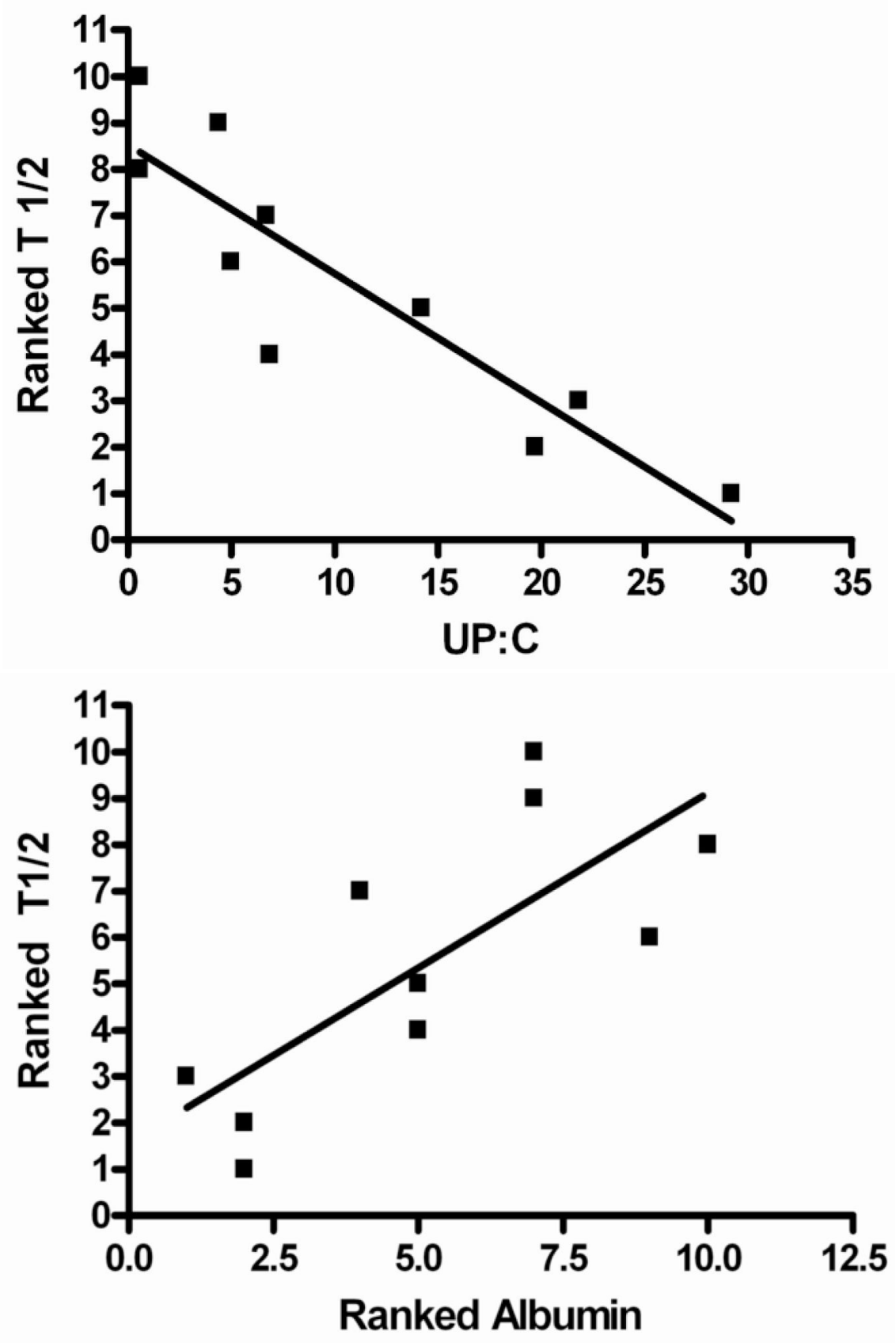

Figures 3a and $3 b$.

3a: Linear regression model of ranked $T_{1 / 2}$ versus UP:C (urine protein-creatinine ratio) at steady state. Data were ranked so that they would follow a normal distribution. The model resulted in $\mathrm{r}=-0.8990$ (95\% Confidence Interval -0.9761 to -0.6207$), \mathrm{r}^{2}-0.6207, \mathrm{p}<0.001$.

3b: Linear regression model of ranked $T_{1 / 2}$ versus ranked serum albumin at steady state. Data were ranked so that they would follow a normal distribution. The model resulted in $\mathrm{r}=0.7586$ (95\% Confidence Interval 0.2467 to 0.9395$), \mathrm{r}^{2} 0.5755, \mathrm{p}=0.01$ 

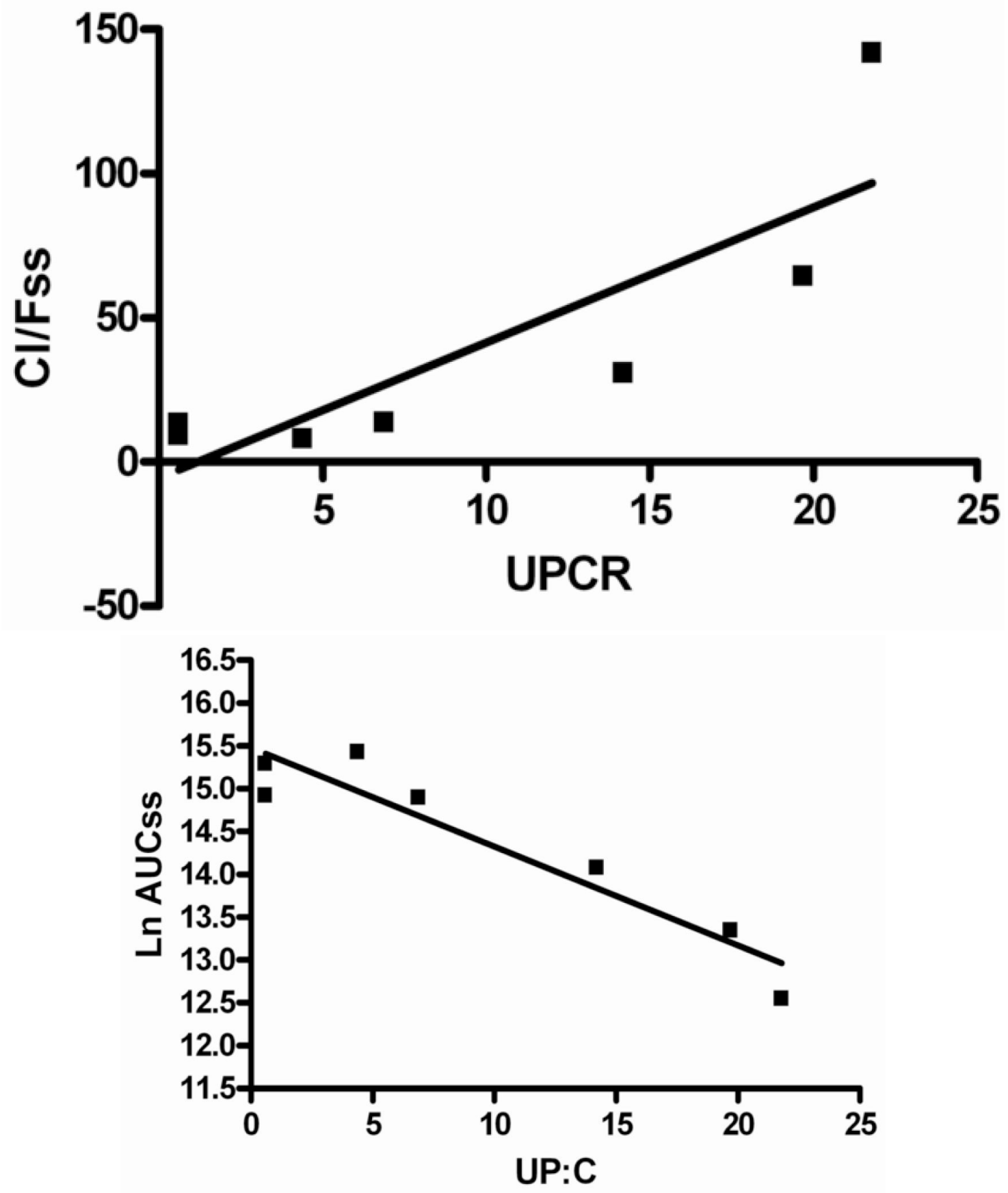

Figures $4 a$ and $4 b$.

4a: Linear regression model of $C l / F_{s s}$ versus UPCR (urine protein-creatinine ratio). The model resulted in $r=0.8465$ (95\% Confidence Interval -0.1615 to -0.0693$), r^{2} 0.7165, p=0.02$. 4b: Linear regression model of $\ln A U C_{S S}$ versus UP:C (urine protein-creatinine ratio). The model resulted in $\mathrm{r}=0.9446$ (95\% Confidence Interval 1.3 to 8.095$), \mathrm{r}^{2} 0.8923, \mathrm{p}=0.001$ 
Table 4

Pharmacokinetic Variables in FSGS compared to Rheumatoid Arthritis

\begin{tabular}{|c|c|c|c|}
\hline & \multicolumn{2}{|l|}{ Single Dose } & \multirow{2}{*}{$\begin{array}{l}\text { Steady State } \\
\text { FSGS }\end{array}$} \\
\hline & FSGS & RA & \\
\hline $\mathrm{T}_{\max }(\mathrm{hr})$ & $55 \pm 62^{a}$ & $130 \pm 55^{\&}$ & $34.2 \pm 9.8$ \\
\hline $\mathrm{C}_{\max }(\mu \mathrm{g} / \mathrm{mL})^{\#}$ & $9.2 \pm 4.1^{a}$ & $13.7 \pm 2.7$ & $12.8 \pm 8.3$ \\
\hline $\mathrm{T}^{1} / 2(\mathrm{hr})$ & $159 \pm 155^{b}$ & $389 \pm 71$ & $273 \pm 402$ \\
\hline $\operatorname{AUC}(\mu \mathrm{g} \mathrm{hr} / \mathrm{mL})^{\#}$ & $1649 \pm 1202^{b}$ & $3622 \pm 587$ & $2019 \pm 1693$ \\
\hline $\mathrm{Cl} / \mathrm{F}(\mathrm{mL} / \mathrm{hr})^{+}$ & $20.2 \pm 8.4^{b, c}$ & $11.2 \pm 2.0$ & $53.2 \pm 43.3$ \\
\hline $\mathrm{Vd} / \mathrm{z}(\mathrm{L})$ & $3.5 \pm 1.3^{b}$ & $5.7 \pm 0.9$ & $6.6 \pm 5.4$ \\
\hline
\end{tabular}

Note: Data are provided as mean \pm SD. FSGS data are from the FONT study, rheumatoid arthritis (RA) values are from a previous study. ${ }^{21}$

AUC data at single dose is $0-\infty$ and at steady state is $0-360$ hours (represents a dosing interval)

${ }^{\&}$ Investigator Brochure cited in ref 21

normalized to a $40 \mathrm{mg}$ dose

${ }^{+}$body weight scaled to a power of $0.75($ ref 21)

${ }^{a}<<0.02$ comparing FSGS single dose and RA single dose

${ }^{b}<0.001$ comparing FSGS single dose and RA single dose

${ }^{c} \mathrm{P}<0.05$ comparing FSGS single dose and FSGS steady state 


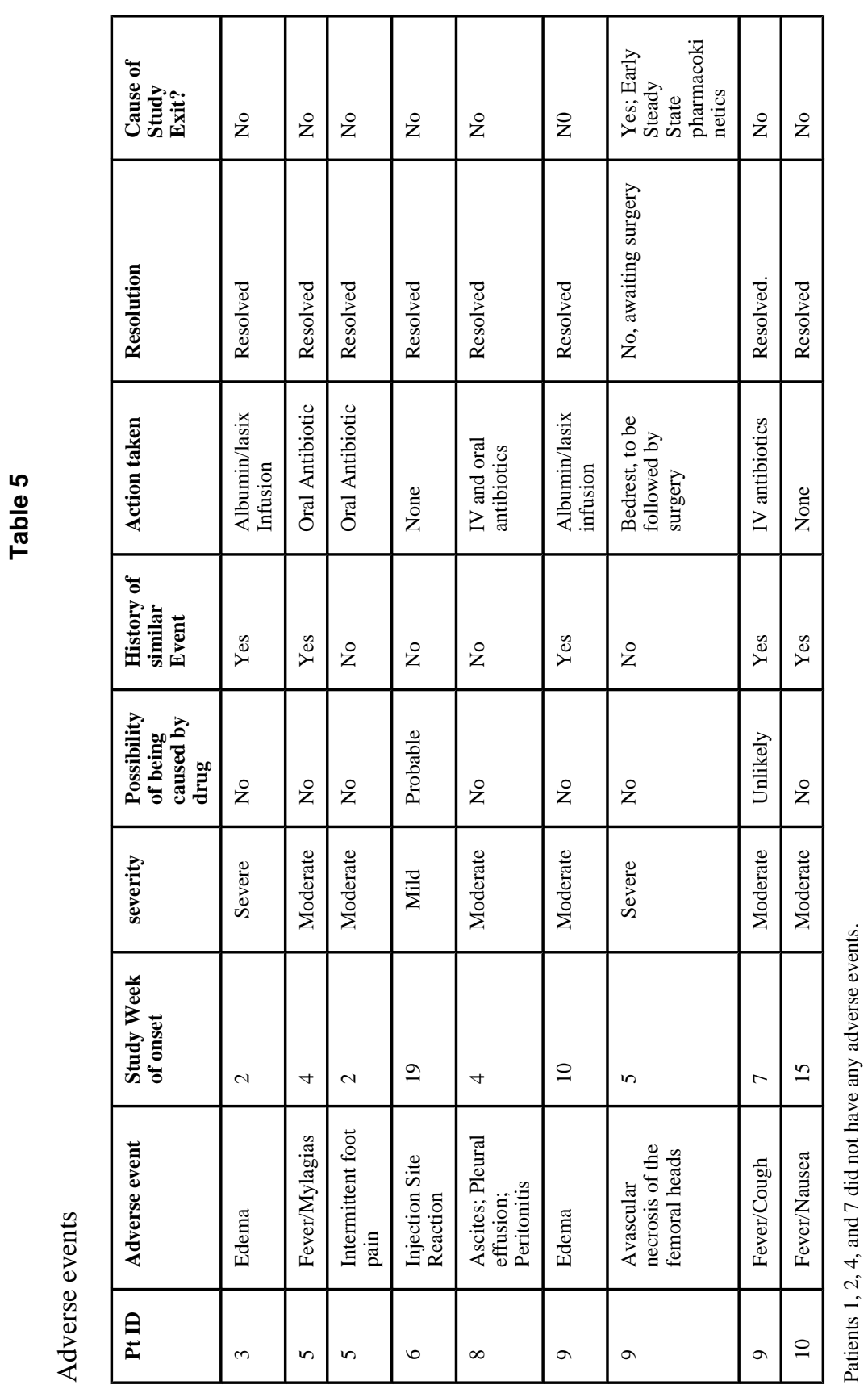

Am J Kidney Dis. Author manuscript; available in PMC 2011 January 1. 